\title{
MONENSINA E DIGESTIBILIDADE APARENTE EM OVINOS ALIMENTADOS COM PROPORÇÕES DE VOLUMOSO/CONCENTRADO'
}

\author{
Paulo Henrique Mazza Rodrigues²*; Wilson Roberto Soares Mattos³; Laércio Melotti²; Renato \\ Ranzini Rodrigues ${ }^{4}$ \\ ${ }^{2}$ Depto. de Nutrição e Produção Animal - USP/FMVZ, Av. Duque de Caxias Norte, 225 - CEP: 13630-000 - \\ Pirassununga, SP. \\ ${ }^{3}$ Depto. de Produção Animal - USP/ESALQ, C.P. 9 - CEP: 13418-900 - Piracicaba, SP. \\ ${ }^{4}$ Pós-Graduando do Depto. de Nutrição e Produção Animal - USP/FMVZ. \\ *Autor correspondente <pmazza@usp.br>
}

\begin{abstract}
RESUMO: A resposta obtida com a utilização dos ionóforos é influenciada por diversos fatores, entre eles a densidade energética da dieta. Foram objetivos do presente estudo avaliar os efeitos da monensina sobre a digestibilidade total em ovinos submetidos a diferentes dietas. Dezoito animais machos e castrados foram distribuídos em um delineamento inteiramente casualizado com um arranjo fatorial de tratamentos $2 \times 3$, correspondentes a zero ou $40 \mathrm{mg}$ de monensina sódica por animal e por dia e $25 \%, 50 \%$ ou $75 \%$ de concentrados na dieta, composta por mistura de concentrados, a base de milho e farelo de soja, e feno de Coast-Cross. O experimento teve duração total de 25 dias, sendo os 5 últimos destinados à coleta de fezes e urina. A monensina aumentou a digestibilidade total da proteína bruta, avaliada através de coleta total de fezes, independentemente do nível de fibra utilizado (25\% de concentrados: $69,6 \%$ vs. $65,3 \% ; 50 \%$ de concentrados: $72,2 \%$ vs. $69,2 \% ; 75 \%$ de concentrados: $73,4 \%$ vs. $69,8 \%$ ). A monensina interagiu com o nível de concentrados da dieta para a digestibilidade total da fibra bruta (25\% de concentrados: $62,0 \%$ vs. $61,0 \%$; $50 \%$ de concentrados: $53,2 \%$ vs. $59,2 \% ; 75 \%$ de concentrados: $51,8 \%$ vs. $42,7 \%)$ e retenção nitrogenada $(25 \%$ de concentrados: $-3,8$ vs. $-20,6 ; 50 \%$ de concentrados: $-10,4$ vs. $+2,0 ; 75 \%$ de concentrados: $+11,4$ vs. $+7,9 \%$ do $\mathrm{N}$ retido em relação ao absorvido), sendo as melhores respostas obtidas na dieta predominantemente concentrada e as piores na dieta mista. Este produto não alterou o consumo de matéria seca, a digestibilidade total da matéria seca, dos extrativos não nitrogenados, do extrato etéreo, da fibra em detergente ácido, da fibra em detergente neutro, da energia bruta e os nutrientes digestíveis totais em qualquer dieta.

Palavras-chave: ionóforos, fibra, digestão, ovinos
\end{abstract}

\section{MONENSIN AND TOTAL TRACT DIGESTIBILITY IN WETHERS FED DIFFERENT ROUGHAGE/CONCENTRATE RATIOS}

\begin{abstract}
The response to the use of ionophores is influenced by several factors, such as the diet energetic density. The objective of this study was to evaluate the effects of monensin on total tract digestibility in ruminants fed with different diets. Eighteen wethers were randomly exposed to three diets with different concentrate levels $(25 \%, 50 \%$ and $75 \%$ ) without (control) or with monensin (40 mg/animal/day). Experimental period extended for twenty-five days, the last five used for feces and urine collection. The diet consisted of CoastCross hay and a concentrate mixture. Monensin increased total tract digestibility of crude protein, independent of the concentrate level (25\%-concentrate: $69.6 \%$ vs. $65.3 \%$; $50 \%$-concentrate: $72.2 \%$ vs. $69.2 \% ; 75 \%$ concentrate: $73.4 \%$ vs. $69.8 \%$ ). There was an interaction between concentrate level and monensin for total tract digestibility of crude fiber (25\%-concentrate: $62.0 \%$ vs. $61.0 \%$; $50 \%$-concentrate: $53.2 \%$ vs. $59.2 \% ; 75 \%$ concentrate: $51.8 \%$ vs. $42.7 \%$ ) and nitrogen balance (25\%-concentrate: -3.8 vs. $-20.6 ; 50 \%$-concentrate: 10.4 vs. $+2.0 ; 75 \%$-concentrate: +11.4 vs. $+7.9 \%$ of absorbed $N$ ). The best response to monensin was obtained for the high-concentrate diet and the worst for the $50 \%$-concentrate. Monensin supplementation did not influence dry matter intake, total tract digestibility of dry matter, ether extract, nitrogen-free extract, acid detergent fiber, neutral detergent fiber, gross energy and total digestible nutrients in any diet. It is concluded that monensin response was greater in either high-concentrate or high-forage diets and worst in the $50 \%$-concentrate diet. Key words: ionophores, fiber, digestion, sheep
\end{abstract}

\section{INTRODUÇÃO}

Antibióticos ionóforos, entre eles a monensina, são moléculas de baixo peso molecular produzidas por cepas de Streptomyces sp. (Ovchinnikov, 1979). Esses aditivos são utilizados extensamente em produção animal por melhorar a eficiência do metabolismo energético e protéico e diminuir a incidência de distúrbios digestivos, resultando em aumentos de produtividade animal (Bergen \& Bates, 1984). As respostas alcançadas

${ }_{1}^{1}$ arte da Tese de Doutorado do primeiro autor, apresentada à USP/ESALQ - Piracicaba, SP. 
com a utilização dos ionóforos, entretanto, são bastantes variáveis, o que pode ser explicado, em parte, pelas diferentes condições experimentais (Galloway et al., 1993).

Pomar et al. (1989) observaram que a monensina diminuiu a digestibilidade da fibra em dietas predominantemente concentradas, mas aumentou a digestibilidade destas frações em dietas predominantemente volumosas. Já McCann et al. (1990) e Araujo-Febres \& Fernández (1991) observaram que a monensina foi capaz de aumentar a digestibilidade da fibra e da proteína à medida em que a proporção de volumosos era diminuída. Outros trabalhos, entretanto, não demonstraram efeitos dos ionóforos sobre a digestibilidade da MS, fibra e PB (Thornton \& Owens, 1981), sobre a digestibilidade da matéria orgânica, fibra, amido e PB (Zinn et al., 1994) ou sobre a digestibilidade da PB (Pomar et al., 1989), qualquer que fosse o nível de fibra na dieta.

Embora vários pesquisadores tivessem demonstrado efeitos benéficos dos ionóforos sobre a digestibilidade ou degradabilidade dos alimentos, outros não demonstraram qualquer efeito ou reportaram efeitos indesejáveis. Lemenager et al. (1978), Simpson (1978) e Poos et al. (1979) registraram que a monensina diminuiu a digestibilidade da fibra ou da MS quando utilizaram animais ou inóculos, quando em experimentos in vitro, não adaptados a este produto.

Os objetivos do presente trabalho foram estudar os efeitos da monensina sobre o consumo de alimentos, sobre a digestibilidade in vivo da matéria seca e nutrientes da dieta e sobre a retenção nitrogenada em carneiros recebendo dietas com diferentes níveis de fibra, uma vez que essa característica da dieta tem se mostrado como o principal fator em determinar a resposta àquele produto.

\section{MATERIAL E MÉTODOS}

O experimento foi realizado nas instalações do Laboratório de Nutrição de Ruminantes da Faculdade de Medicina Veterinária e Zootecnia da USP - Campus de Pirassununga-SP.

Foram utilizados dezoito ovinos deslanados, adultos, machos, mestiços da raça Santa Inês, com peso vivo médio de $56,2 \mathrm{~kg}$ ao início do experimento. Os animais foram mantidos em gaiolas metabólicas providas de cocho e bebedouro individuais, sendo os mesmos arreados com bolsas coletoras. Foi utilizado o delineamento inteiramente casualizado com um arranjo fatorial de tratamentos do tipo $2 \times 3$, correspondendo ao fator monensina sódica na dosagem de zero e $40 \mathrm{mg}$ por animal por dia e três proporções de concentrados na dieta: $25 \%, 50 \%$ e $75 \%$. A monensina sódica (Rumensin ${ }^{\circledR}$ ELANCO) foi pesada em balança analítica e administrada aos animais durante o momento das refeições, sendo misturada ao concentrado por meio de mistura manual.
As dietas foram formuladas para serem isonitrogenadas (TABELA 1) e a ração foi fornecida em duas refeições, às $8 \mathrm{~h} 00$ e $16 \mathrm{~h} 00$, na forma de mistura completa, sendo compostas as proporções volumoso:concentrado com base na matéria seca. 0 consumo durante o período de coleta de fezes foi restrito a $80 \%$ do ad libitum durante o período de adaptação. Amostras da dieta (feno e misturas concentradas) foram coletadas diariamente durante o período, de forma a comporem uma amostra composta.

O experimento teve duração total de 25 dias, dos quais os primeiros 17 dias foram destinados à adaptação dos animais às dietas. Entre $018^{\circ}$ e o $25^{\circ}$ dias foi feita a restrição do consumo e entre $021^{\circ}$ e o $25^{\circ}$ dia a coleta de fezes, urina e ingredientes da dieta para avaliação da digestibilidade in vivo e retenção nitrogenada.

As coletas de fezes, obtidas das bolsas coletoras, foram realizadas uma vez ao dia e unidas para formar uma amostra composta. Após serem pesadas, uma amostra de $10 \%$ foi processada em estufa de ar forçado a $65^{\circ} \mathrm{C}$, por 72 horas após a amostragem do último dia de coleta. A urina foi coletada em baldes plásticos contendo ácido clorídrico concentrado 1:1, na proporção de $20 \mathrm{~mL}$ de ácido para cada litro de urina produzida durante o período de adaptação. Uma amostra composta referente a $10 \%$ do total produzido foi armazenada a $5^{\circ} \mathrm{C}$ até o momento de realização das análises. As análises bromatológicas de MS, PB, FB e MM foram realizadas segundo AOAC (1980) e de FDN e FDA segundo Goering \& Van Soest (1970).

Os resultados foram submetidos à análise de variância, que separou como causas de variação efeito de proporção de concentrados, efeito de monensina e efeito de interação (SAS, 1985). Os efeitos da proporção de concentrados foram separados, através do uso de polinômios ortogonais, em efeito linear e desvio da linearidade, enquanto que a interação entre os fatores estudados foi separada através da metodologia de comparação de retas (lineares ou com desvio da linearidade) para o fator presença de monensina. Para tal análise, foi utilizado o procedimento General Linear Model (PROC GLM do SAS), adotando-se o nível de significância de $5 \%$ para os testes realizados. Os dados de digestibilidade foram ajustados, através da metodologia dos quadrados mínimos, para covariável consumo de matéria seca.

\section{RESULTADOS E DISCUSSÃO}

Não foi possível detectar efeitos do nível de concentrados da dieta ou presença de monensina sobre o consumo de matéria seca, independentemente da maneira com que os dados fossem expressos (TABELA 2). Goodrich et al. (1984) observaram que a média na queda do consumo causada pela monensina era da ordem de $6,4 \%$. A falta de efeitos da monensina sobre o consumo, qualquer que fosse a dieta, não permite 
TABELA 1 - Proporções de ingredientes e composição bromatológica das rações utilizadas no experimento, com base na matéria seca.

\begin{tabular}{|c|c|c|c|}
\hline \multirow[b]{2}{*}{ Ing rediente (\%) } & \multicolumn{3}{|c|}{ Proporção de Concentrado } \\
\hline & $25 \%$ & $50 \%$ & $75 \%$ \\
\hline Feno de Coast-cross & 75,0 & 50,0 & 25,0 \\
\hline Grãos de Milho moído & 21,6 & 44,7 & 67,7 \\
\hline Farelo de soja & 1,90 & 3,80 & 5,80 \\
\hline Sal branco & 0,50 & 0,50 & 0,50 \\
\hline \multirow{2}{*}{ Mistura mineral ${ }^{1}$} & 1,00 & 1,00 & 1,00 \\
\hline & 100,0 & 100,0 & 100,0 \\
\hline \multicolumn{4}{|l|}{ Composição (\%) } \\
\hline MS & 91,10 & 90,70 & 90,30 \\
\hline PB & 12,78 & 13,07 & 13,35 \\
\hline Prote ína não degradável & 33,57 & 37,20 & 40,68 \\
\hline Proteína degradável & 66,43 & 62,80 & 59,32 \\
\hline FDA & 28,46 & 20,90 & 13,35 \\
\hline FDN & 58,57 & 45,37 & 32,16 \\
\hline FDN efetivo & 55,18 & 38,37 & 21,55 \\
\hline EE & 1,77 & 2,39 & 3,01 \\
\hline MM & 8,01 & 6,09 & 4,17 \\
\hline Carboidratos não estrut. & 17,87 & 32,08 & 46,30 \\
\hline NDT estimado & 57,17 & 65,59 & 74,02 \\
\hline $\mathrm{Ca}$ & 0,55 & 0,49 & 0,42 \\
\hline $\mathrm{P}$ & 0,34 & 0,35 & 0,36 \\
\hline
\end{tabular}

${ }^{1}$ Composição por kg de mistura mineral: $180 \mathrm{~g} \mathrm{Ca}, 90 \mathrm{~g} \mathrm{P}, 20 \mathrm{~g} \mathrm{Mg}, 20 \mathrm{~g} \mathrm{~S}, 100 \mathrm{~g} \mathrm{Na}, 155 \mathrm{~g} \mathrm{Cl}, 3.000 \mathrm{mg} \mathrm{Zn}, 1.000$ mg Cu, $1.250 \mathrm{mg} \mathrm{Mn}$, $2.000 \mathrm{mg}, \mathrm{Fe}, 100 \mathrm{mg} \mathrm{Co}, 90 \mathrm{mg} \mathrm{I}, 20 \mathrm{mg} \mathrm{Se}, 900 \mathrm{mg} \mathrm{F}$ (máximo).

confirmar a hipótese postulada por Schelling (1984) de que os ionóforos deprimem o consumo voluntário de alimentos quando os animais são alimentados com dietas predominantemente concentradas, mas podem incrementar o consumo em condições de pastejo. Também não foi possível confirmar a hipótese postulada por Baile et al. (1979), que afirmaram que os ionóforos reduzem o consumo de alimentos em qualquer tipo de dieta, embora com maiores efeitos em dietas predominantemente concentradas.

Embora os resultados não tenham sido estatisticamente significativos, a monensina pouco alterou o consumo na dieta predominantemente volumosa, diminuiu bastante (36,7\%) o consumo na dieta mista, e aparentemente não alterou o consumo na dieta predominantemente concentrada. Isto corrobora os dados obtidos por Arcaro (1998), que reportou que os ionóforos deprimem mais o consumo em dietas mistas, quando comparadas com as predominantemente volumosas. Portanto, é bem provável que a monensina deprima mais o consumo em dietas concentradas, como postulado por Schelling (1984) e Baile et al. (1979), mas se esta dieta for excessivamente concentrada, e potencialmente acidogênica, é possível que esse produto melhore as condições de fermentação ruminal, permitindo manter consumo. Neste caso, entretanto, há que se considerar que, em dietas altamente energéticas, o consumo seja mais influenciado por aspectos fisiopatológicos ( $\mathrm{pH}$ ruminal excessivamente baixo) antes que pela produção de ácido propiônico (disparador do gatilho da saciedade em ruminantes).

Os resultados deste ensaio concordam com muitos outros que não observaram efeitos dos ionóforos sobre o consumo de alimentos nas mais diversas condições (Dinius et al., 1976; Ricke et al., 1984; Branine \& Galyean, 1990; Galloway et al., 1993; Yang \& Russell, 1993). Zinn et al. (1994), Rodrigues (1996) e Ramanzin et al. (1997) ainda afirmam que a ausência de resposta independe da proporção de concentrados da dieta.

Houve efeito linear da proporção de concentrados sobre a retenção nitrogenada expressa em gramas de nitrogênio retido por animal por dia $(\mathrm{RNg})$. A retenção foi aumentada em 1,0 e 2,9 gramas de N/ animal/dia nas dietas mista e predominantemente concentrada, respectivamente, quando comparadas com a dieta predominantemente volumosa (TABELA 2). Para a retenção nitrogenada expressa como porcentagem do nitrogênio retido em relação ao total de nitrogênio absorvido ( $R N \%$ ) houve interação entre dose de monensina e proporção de concentrados na ração. Quando separadas as interações, observou-se um comportamento curvilinear de resposta, de forma que a 
adição de monensina na dieta aumentou a retenção nitrogenada em 16,8 e 3,5 unidades percentuais para as dietas predominantemente volumosas e concentradas, respectivamente, mas diminuiu este parâmetro em 12,5 unidades percentuais na dieta mista (Figura 1).

Dinius et al. (1976) também demostraram aumento da retenção nitrogenada com a utilização de monensina na dieta de animais alimentados exclusivamente com volumosos, enquanto que Joyner et al. (1979) e Ricke et al. (1984) também o demonstraram em dietas mistas. Outros pesquisadores, entretanto, não observaram efeito dos ionóforos sobre a retenção nitrogenada (Thornton \& Owens, 1981; Rogers \& Davis, 1982), embora Rogers \& Davis (1982) tivessem observado aumento da digestibilidade. Thornton \& Owens (1981) também não demonstraram efeitos dos ionóforos sobre este parâmetro e notaram, ainda, que esta resposta não dependia da porcentagem de fibra na dieta. Isto discorda dos resultados presentes, embora a interpretação seja duvidosa, em decorrência do comportamento curvilinear aqui obtido. É bastante provável que a diminuição na retenção nitrogenada com a utilização da monensina na dieta mista seja reflexo da queda de consumo de MS obtida nesta condição, e conseqüente menor disponibilidade de energia, embora esta queda no consumo não tenha apresentado um resultado estatisticamente significativo.

O aumento da proporção de concentrados na dieta aumentou linearmente a digestibilidade aparente da proteína bruta em 3,3 a 4,1 unidades percentuais $(4,8 \%$ a $6,1 \%)$, em relação à dieta mais volumosa (TABELA 3). A monensina também aumentou a digestibilidade da proteína bruta em 3,6 unidades percentuais $(5,3 \%)$, independentemente do nível de fibra na dieta (Figura 1).

Os dados do presente trabalho substanciam os achados de outros pesquisadores que observaram aumento da digestibilidade aparente da proteína bruta com o emprego de ionóforos na dieta (Joyner et al., 1979; Rogers \& Davis, 1982; Ricke et al., 1984; Galloway et al., 1993). Atualmente aceita-se que os ionóforos possam diminuir a deaminação (Russell et al., 1988; Chen \& Russell, 1991; Van Kessel \& Russell, 1992), fazendo com que peptídeos e aminoácidos protegidos da deaminação possam ser convertidos em proteína microbiana por cepas resistentes ao ionóforo (Yang \& Russell, 1993).

A ausência de interação entre dose de monensina e proporção de concentrados, encontrada no presente experimento, sugere que o efeito da monensina em aumentar a digestibilidade da PB independe do nível de fibra na dieta, embora Araujo-Febres \& Fernández (1991) e McCann et al. (1990) tivessem demonstrado maior efeito do produto em dietas predominantemente concentradas.

Outros autores não observaram efeitos dos ionóforos sobre a digestibilidade da PB (Dinius et al., 1976; Johnson Jr. et al., 1988; Marounek et al., 1989;
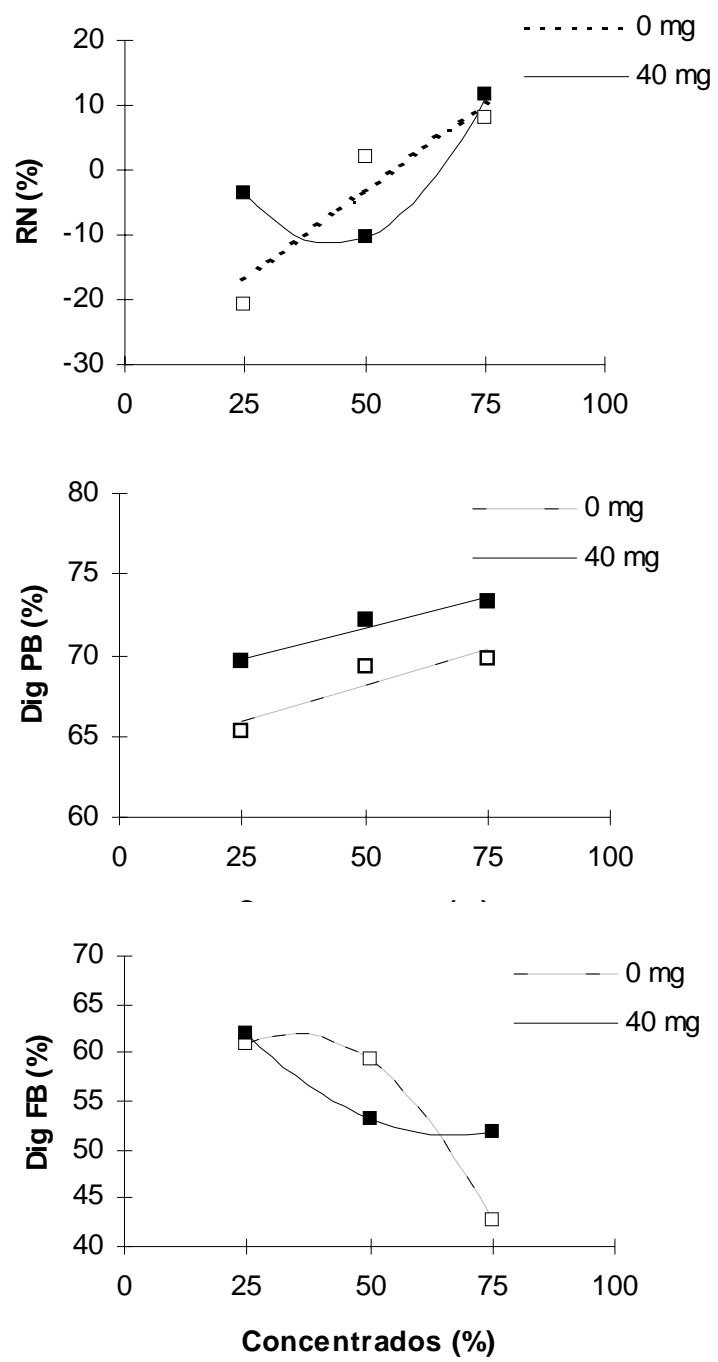

Figura 1 - Efeitos da proporção de concentrados (\% da dieta) e dose de monensina ( 0 ou $40 \mathrm{mg}$ animal ${ }^{-1} \mathrm{dia}^{-1}$ ) sobre a retenção nitrogenada, expressa em porcentagem de nitrogênio retido em relação ao nitrogênio absorvido $(0$ mg de Mon: $\mathrm{RN} \%=-30,37+0,545 \mathrm{Con}, \mathrm{R}^{2}=0,7261 ; 40$ mg de Mon: $R N \%=31,39-1,977$ Con $+0,023$ Con $^{2}$, $\left.\mathrm{R}^{2}=0,7178\right)$, e sobre a digestibilidade aparente (em \%) da proteína bruta $(0 \mathrm{mg}$ de Mon: DigPB $=63,67+0,089 \mathrm{Con}$, $\mathrm{R}^{2}=0,2474 ; 0 \mathrm{mg}$ de Mon: DigPB $=67,95+0,075$ Con, $\left.\mathrm{R}^{2}=0,5509\right)$ e fibra bruta ( $0 \mathrm{mg}$ de Mon: DigFB $=48,20$ $+0,805$ Con $-0,0117 \mathrm{Con}^{2}, \mathrm{R}^{2}=0,8827 ; 40 \mathrm{mg}$ de Mon: DigFB $=78,12-0,795$ Con $\left.+0,0059 \mathrm{Con}^{2}, \mathrm{R}^{2}=0,5570\right) \mathrm{da}$ dieta, quando corrigidos para o consumo diário de matéria seca $\left(\mathrm{kg} \mathrm{dia}^{-1}\right)$.

Pomar et al., 1989). Thornton \& Owens (1981) e Zinn et al. (1994) observaram ainda que a ausência de efeitos independia do nível de fibra da dieta.

A digestibilidade aparente da fibra bruta apresentou interação entre a proporção de concentrados na ração e a presença da monensina na dieta (Figura 1). A interação não apresentou comportamento linear, de forma que a presença de ionóforos aumentou a digestibilidade desta fração em 9,1 unidades percentuais $(21,4 \%)$ na dieta predominantemente concentrada, mas a diminuiu em 6,0 unidades percentuais $(10,1 \%)$ na dieta mista. 
TABELA 2 - Efeitos da proporção de concentrados (Con) e dose de monensina (Mon) sobre o consumo e retenção nitrogenada, coeficientes de variação (CV) e probabilidades estatísticas ${ }^{1}$.

\begin{tabular}{|c|c|c|c|c|c|c|c|}
\hline \multicolumn{2}{|c|}{ Tratamento } & \multicolumn{4}{|c|}{ Consumo } & \multicolumn{2}{|c|}{ Retenção Nitrogenada } \\
\hline Con & Mon & CMS & $\mathrm{CMS} / \mathrm{PV}$ & $\mathrm{CMS} / \mathrm{P}^{0,75}$ & CNDT & $\mathrm{RNg}$ & RN\% \\
\hline \multicolumn{8}{|c|}{ Interação } \\
\hline \multirow[t]{2}{*}{25} & 0 & 1,08 & 2,05 & 55,09 & 0,67 & $-2,55$ & $-20,61$ \\
\hline & 40 & 1,17 & 1,98 & 54,75 & 0,73 & $-0,40$ & $-3,77$ \\
\hline \multirow[t]{2}{*}{50} & 0 & 1,20 & 2,39 & 63,64 & 0,84 & 0,35 & 2,04 \\
\hline & 40 & 0,76 & 1,39 & 37,75 & 0,53 & $-0,94$ & $-10,42$ \\
\hline \multirow[t]{2}{*}{75} & 0 & 1,32 & 2,46 & 66,64 & 0,98 & 1,27 & 7,94 \\
\hline & 40 & 1,38 & 2,39 & 65,92 & 1,05 & 2,02 & 11,44 \\
\hline \multicolumn{8}{|c|}{ Efeito Principal } \\
\hline \multicolumn{2}{|l|}{25} & 1,13 & 2,00 & 54,89 & 0,70 & $-1,26$ & $-10,51$ \\
\hline \multicolumn{2}{|l|}{50} & 0,98 & 1,89 & 50,70 & 0,68 & $-0,30$ & $-4,19$ \\
\hline \multicolumn{2}{|l|}{75} & 1,35 & 2,43 & 66,28 & 1,01 & 1,64 & 9,69 \\
\hline & 0 & 1,22 & 2,33 & 62,63 & 0,85 & $-0,03$ & $-1,41$ \\
\hline & 40 & 1,10 & 1,92 & 52,81 & 0,77 & 0,23 & $-0,92$ \\
\hline \multicolumn{8}{|c|}{ Média } \\
\hline \multicolumn{2}{|l|}{ Média } & 1,16 & 2,11 & 57,43 & 0,81 & 0,11 & $-1,15$ \\
\hline \multicolumn{2}{|l|}{ CV } & 28,91 & 25,77 & 26,22 & 31,36 & $1.675,60$ & $1.081,66$ \\
\hline \multicolumn{8}{|c|}{ Significância } \\
\hline \multicolumn{8}{|c|}{ Concentrado } \\
\hline \multicolumn{2}{|c|}{ Linear (L) } & NS & NS & NS & 0,0289 & 0,0016 & 0,0009 \\
\hline \multicolumn{2}{|c|}{ Desvio (D) } & NS & NS & NS & NS & NS & NS \\
\hline \multicolumn{2}{|c|}{ Monensina } & NS & NS & NS & NS & NS & NS \\
\hline \multicolumn{8}{|c|}{ Interação } \\
\hline \multicolumn{2}{|c|}{ Linear $x$ linear } & NS & NS & NS & NS & NS & NS \\
\hline \multicolumn{2}{|c|}{ Desvio $x$ desvio } & NS & NS & NS & NS & NS & 0,0171 \\
\hline
\end{tabular}

${ }^{1} \mathrm{CMS}$ : consumo diário de matéria seca (em quilos), CMS/PV: consumo diário de matéria seca por quilo de peso vivo (em porcentagem do peso vivo), CMS/P0,75: consumo diário de matéria seca por quilo de peso metabólico (em gramas), CNDT: consumo diário de nutrientes disgetíveis totais (em quilos), RNg: retenção nitrogenada (gramas de nitrogênio por animal por dia), RN\%: retenção nitrogenada (porcentagem em relação ao nitrogênio absorvido).

Resultados semelhantes foram observados por McCann et al. (1990) e por Araujo-Febres \& Fernández (1991) ao demonstrarem que a digestibilidade aparente da FDN e da FB aumentavam, respectivamente, com o uso de ionóforos, e que esse aumento era maior a medida em que a proporção de concentrados era aumentada.

Pomar et al. (1989) observaram que a monensina diminuía a digestibilidade da FDN e FDA em dietas predominantemente concentradas, mas aumentava a digestibilidade destas frações fibrosas em dietas predominantemente volumosas, enquanto que Thornton \& Owens (1981) e Zinn et al. (1994) não demonstraram efeitos dos ionóforos sobre a digestibilidade da fibra, independentemente do nível de fibra da dieta. Poos et al. (1979) observaram, ainda, diminuição da digestibilidade da FDA em animais não adaptados à monensina, mas não nos adaptados.

O efeito dos ionóforos sobre a digestibilidade da fibra tem sido comumente explicado na literatura como sendo decorrente do aumento do tempo de retenção da
MS no rúmen (Ellis et al., 1983), decorrente do menor consumo voluntário de alimentos (Rogers \& Davis, 1982), melhora das condições ruminais (Branine \& Galyean, 1990) ou aumento do estímulo à ruminação (Knowlton et al., 1996). Os efeitos da monensina sobre a digestibilidade da fibra, entretanto, se mantiveram mesmo após correção para o consumo de matéria seca. Este achado contradiz a hipótese formulada por Ellis et al. (1983) e Rogers \& Davis (1982).

A queda da digestibilidade da fibra pelo uso de concentrados apresentou resposta linear e chegou a 5,3 unidades percentuais (8,6\%) para a dieta mista e 16,8 unidades percentuais $(27,1 \%)$ para a dieta predominantemente concentrada, quando comparadas à dieta predominantemente volumosa.

Assim como observado por Thornton \& Owens (1981) e Zinn et al. (1994), nenhum efeito da monensina foi notado sobre a digestibilidade da MS, independentemente da característica da dieta. Embora seja aceito que os ionóforos causem pequena a 
TABELA 3 - Efeitos da proporção de concentrados (Con) e dose de monensina (Mon) sobre a digestibilidade aparente (em \%) da MS da dieta e suas frações, quando corrigidos para o consumo diário de matéria seca ( $\mathrm{kg} / \mathrm{dia})$, coeficientes de variação (CV) e probabilidades estatísticas'.

\begin{tabular}{|c|c|c|c|c|c|c|c|c|c|c|}
\hline \multicolumn{2}{|c|}{ Tratamento } & \multicolumn{9}{|c|}{ Fração } \\
\hline Con & Mon & MS & PB & FB & ENN & $\mathrm{EE}$ & NDT & FDN & FDA & EB \\
\hline \multicolumn{11}{|c|}{ Interação } \\
\hline \multirow[t]{2}{*}{25} & 0 & 65,08 & 65,33 & 61,01 & 67,98 & 66,75 & 61,37 & 60,13 & 54,89 & 61,70 \\
\hline & 40 & 66,07 & 69,60 & 61,95 & 68,66 & 64,82 & 62,35 & 61,82 & 57,04 & 62,91 \\
\hline \multirow[t]{2}{*}{50} & 0 & 71,82 & 69,24 & 59,17 & 77,14 & 77,19 & 69,89 & 61,24 & 56,74 & 70,03 \\
\hline & 40 & 70,69 & 72,18 & 53,18 & 77,03 & 74,01 & 68,76 & 58,19 & 52,59 & 66,95 \\
\hline \multirow[t]{2}{*}{75} & 0 & 74,79 & 69,77 & 42,68 & 81,75 & 81,53 & 75,05 & 52,71 & 46,03 & 72,77 \\
\hline & 40 & 76,99 & 73,36 & 51,81 & 83,19 & 80,08 & 77,29 & 58,60 & 52,36 & 75,32 \\
\hline \multicolumn{11}{|c|}{ Efeito Principal } \\
\hline 25 & & 65,58 & 67,46 & 61,48 & 68,32 & 65,79 & 61,86 & 60,97 & 55,96 & 62,30 \\
\hline 50 & & 71,29 & 70,71 & 56,17 & 77,09 & 75,60 & 69,33 & 59,71 & 54,67 & 68,49 \\
\hline \multirow[t]{3}{*}{75} & & 75,89 & 71,57 & 47,24 & 82,47 & 80,80 & 76,17 & 55,65 & 49,20 & 74,04 \\
\hline & 0 & 70,56 & 68,12 & 54,29 & 75,63 & 75,16 & 68,77 & 58,02 & 52,55 & 68,17 \\
\hline & 40 & 71,25 & 71,71 & 55,64 & 76,29 & 72,97 & 69,47 & 59,53 & 54,00 & 68,39 \\
\hline \multicolumn{11}{|c|}{ Média } \\
\hline \multicolumn{2}{|l|}{ Média } & 71,25 & 70,18 & 54,61 & 76,43 & 74,49 & 69,58 & 58,70 & 53,18 & 68,67 \\
\hline \multicolumn{2}{|l|}{ CV } & 5,94 & 4,80 & 16,27 & 7,56 & 8,92 & 8,27 & 9,42 & 10,19 & 7,42 \\
\hline \multicolumn{11}{|c|}{ Significância } \\
\hline \multicolumn{11}{|c|}{ Concentrado } \\
\hline \multicolumn{2}{|c|}{ Linear (L) } & 0,0001 & 0,0261 & 0,0001 & 0,0001 & 0,0001 & 0,0001 & 0,0319 & 0,0145 & 0,0001 \\
\hline \multicolumn{2}{|c|}{ Desvio (D) } & NS & NS & NS & 0,0387 & NS & NS & NS & NS & NS \\
\hline \multicolumn{2}{|c|}{ Monensina } & NS & 0,0139 & NS & NS & NS & NS & NS & NS & NS \\
\hline \multicolumn{11}{|c|}{ Interação } \\
\hline \multicolumn{2}{|c|}{ Lin. $X$ lin. } & NS & NS & NS & NS & NS & NS & NS & NS & NS \\
\hline \multicolumn{2}{|c|}{ Des. $X$ des. } & NS & NS & 0,0257 & NS & NS & NS & NS & NS & NS \\
\hline
\end{tabular}

${ }^{1} \mathrm{MS}$ : digestibilidade da matéria seca (\%), PB: : digestibilidade da proteína bruta (\%), FB: digestibilidade da fibra bruta (\%), ENN: digestibilidade do extrativo não-nitrogenado (\%), EE: digestibilidade do extrato etéreo (\%), NDT: nutrientes digestíveis totais (\%), FDN: digestibilidade da fibra em detergente neutro (\%), FDA: digestibilidade da fibra em detergente ácido (\%), EB: digestibilidade da energia bruta (\%).

moderada melhora na digestibilidade dos alimentos (Schelling, 1984), essas condições não estão definidas até o presente momento, podendo sofrer interferência de fatores como consumo de alimentos, enchimento ruminal, taxa de passagem ou outros.

Foi observado aumento linear do NDT e da digestibilidade aparente da energia bruta e aumento curvilinear da digestibilidade aparente do extrativo não nitrogenado somente em função do aumento de concentrados na dieta, mas não em função da dose de monensina. Como resultado do aumento do NDT, causado pelo aumento da proporção de concentrados da dieta, observou-se também aumento do consumo desta fração pelos animais (TABELA 2).

Diferentemente do aqui observado, Johnson Jr. et al. (1988) e Marounek et al. (1989) relataram aumento da digestibilidade dos lipídios com o uso de ionóforos em dietas suplementadas com gordura. Entretanto, o presente experimento apresentou teores de extrato etéreo baixos ( $1,8 \%$ a $3,0 \%)$, quando comparados aos experimentos aqui citados, sendo esta fração constituída possivelmente em sua maioria por compostos de baixa digestibilidade, como ceras e pigmentos. $\mathrm{O}$ aumento linear na digestibilidade desta fração solúvel em solventes orgânicos entre 11,1 e 13,8 unidades percentuais $(16,8 \%$ e $20,9 \%$ ) das dietas mistas e concentradas, respectivamente, em relação à dieta volumosa, é provavelmente decorrente da substituição de compostos indigestíveis formados por ceras e pigmentos, contidos no volumoso, por triglicerídios e fosfolípides dos alimentos concentrados.

Conclui-se, portanto, que os efeitos da monensina sobre a digestibilidade dos alimentos são relativamente pequenos e dependem do nível de fibra da dieta, sendo as melhores respostas observadas principalmente nas dietas predominantemente concentradas ou predominantemente volumosas, quando comparadas às piores respostas obtidas nas dietas mistas. Conclui-se também que estes efeitos não são oriundos totalmente da depressão sobre o consumo, uma vez que estes continuaram evidentes, mesmo após a correção da digestibilidade para a covariável consumo. 


\section{REFERÊNCIAS BIBLIOGRÁFICAS}

ASSOCIATION OF OFFICIAL ANALYTICAL CHEMISTS. Official methods of analysis. 10.ed. Washington: AOAC, 1980. 1015p.

ARAUJO-FEBRES, O.; FERNÁNDEZ, M.C. Efecto en novillos del monensin y el nivel de fibra de la dieta sobre el consumo y la digestibilidad de la materia seca. Revista de la Facultad de Agronomía. Universidad del Zulia, v.8, p.143-153, 1991.

ARCARO, J.R.P. Efeitos da lasalocida sódica sobre o desempenho e composição do leite de vacas Holandesas e Pardo Suíças. Pirassununga, 1998. 96p. Dissertação (Mestrado) - Faculdade de Medicina Veterinária e Zootecnia, Universidade de São Paulo.

BAILE, C.A.; McLAUGHLIN, C.L.; POTTER, E.L.; CHALUPA, W. Feeding behavior changes of cattle during introduction of monensin with roughage or concentrate diets. Journal of Animal Science, v.48, p.1501-1508, 1979.

BERGEN, W.G.; BATES, D.B. Ionophores: Their effect on production efficiency and mode of action. Journal of Animal Science, v.58, p.1465-1483, 1984.

BRANINE, M.E.; GALYEAN, M.L. Influence of grain and monensin supplementation on ruminal fermentation, intake, digesta kinetics and incidence and severity of frothy bloat in steers grazing winter wheat pasture. Journal of Animal Science, v.68, p.1139-1150, 1990.

CHEN, G.; RUSSELL, J.B. Effect of monensin and a protonophore on protein degradation, peptide accumulation, and deamination by mixed ruminal microorganisms in vitro. Journal of Animal Science, v.69, p.2196-2203, 1991.

DINIUS, D.A.; SIMPSON, M.S.; MARSH, P.B. Effect of monensin with forage on digestion and the ruminal ecosystem of steers. Journal of Animal Science, v.42, p.229-234, 1976.

ELLIS, W.C.; HORN G.W.; DELANEY, D.; POND, K.R. Effects of ionophores on grazed forage utilization and their economic value for cattle on wheat pasture. In: NATIONAL WHEAT PASTURE SYMPOSIUM, Stillwater, 1983. Proceedings. Stillwater: Agricultural Experimental Station, 1983. p.343.

GALLOWAY Sr., D.L.; GOETSCH, A.L.; PATIL, A.; FORSTER JR.; L.A.; JOHNSON, Z.B. Feed intake and digestion by Holstein steer calves consuming low-quality grass supplemented with lasalocid or monensina. Canadian Journal of Animal Science, v.73, p.869-879, 1993.

GOERING, H.K.; VAN SOEST, P.J. Forage fiber analysis: apparatus, reagents, procedures and some applications. Washington: Agricultural Research Service, 1970. 379p.

GOODRICH, R.D.; GARRET, J.E.; GAST, D.R.; KIRICK, M.A.; LARSON, D.A.; MEISKE, J.C. Influence of monensin on the performance of cattle. Journal of Animal Science, v.58, p.1484-1498, 1984.

JOHNSON JR., J.C.; UTLEY, P.R.; MULLINIX JR., B.G.; MERRILL, A. Effects of adding fat and lasalocid to diets of dairy cows. Journal of Dairy Science, v.71, p.2151-2165, 1988.

JOYNER, A.E.; BROWN, L.J.; FOGG, T.J.; ROSSI, R.T. Effects of monensin on growth, feed efficiency and energy metabolism of lambs. Journal of Animal Science, v.48, p.1065-1069, 1979.

KNOWLTON, K.F.; ALLEN, M.S.; ERICKSON, P.S. Lasalocid and particle size of corn for dairy cows in early lactation: 2 . Effect on ruminal measurements and feeding behavior. Journal of Dairy Science, v.79, p.565-574, 1996.

LEMENAGER, R.P.; OWENS, F.N.; SHOCKEY, B.J.; LUSBY, K.S.; TOTUSEK, R. Monensin effects on rumen turnover rate, twenty-four hour VFA pattern, nitrogen components and cellulose disappearance. Journal of Animal Science, v.47, p.255-261, 1978
MAROUNEK, M.; SKRIVANOVÁ, V.; MACHAÑOVÁ, L. Effect of monensin on digestibility of nutrients, ruminal volatile fatty acids and parameters in young calves. Landwirtschaftliche Forschung, v.42, p.273-280, 1989.

MCCANN, M.A.; CRADDOCH, B.F.; PRESTON, R.L.; RANSEY, C.B. Digestibility of cotton plant by-products diets for sheep at two levels of intake. Journal of Animal Science, v.68, p.285-295, 1990.

OVCHINNIKOV, J.A. Physico chemical basis of ion transport through biological membranes: Ionophores and ion channels. European Journal of Biochemistry, v.94, p.321-336, 1979.

POMAR, C.; BERNIER, J.F.; SEOANE, F.R.; LATRILLE, L. Highroughage rations with or without monensin for veal production. 2.Ration digestibility. Canadian Journal of Animal Science, v.69, p.403-410, 1989.

POOS, M.I.; HANSON, T.L.; KLOPFENSTEIN, T.J. Monensin effects on diet digestibility, ruminal protein bypass and microbial protein synthesis. Journal of Animal Science, v.48, p.1516-1524, 1979.

RAMANZIN, M.; BAILONI, L.; SCHIAVON, S.; BITTANTE, G. Effect of monensin on milk production and efficiency of dairy cows fed two diets differing in forage to concentrate ratios. Journal of Dairy Science, v.80, p.1136-1142, 1997.

RICKE, S.C.; BERGER, L.L.; VAN DER AAR, P.J.; FAHEY, G.C. Effects of lasalocid and monensin on nutrient digestion, metabolism and rumen characteristics of sheep. Journal of Animal Science, v.58, p.194-202, 1984.

RODRIGUES, P.H.M. Efeitos da lasalocida sódica e proporção volumoso/concentrados sobre a fermentação ruminal e degradabilidade in situ do farelo de soja e do feno Coast Cross (Cynodon dactylon). Pirassununga, 1996. 135p. Dissertação (Mestrado) - Faculdade de Medicina Veterinária e Zootecnia, Universidade de São Paulo.

ROGERS, J.A.; DAVIS, C.L. Rumen volatile fatty acid production and nutrient utilization in steers fed a diet supplemented with sodium bicarbonate and monensin. Journal of Dairy Science, v.65, p.944-952, 1982.

RUSSELL, J.B.; STROBEL, H.J.; CHEN, G. The enrichment and isolation of a ruminal bacterium with a very high specific activity of ammonia production. Applied and Environmental Microbiology, v.54, p.872, 1988.

SAS INSTITUTE. SAS user's guide: statistics. 5.ed. Cary: Statistical Analysis System Intitute, 1985.

SCHELLING, G.T. Monensin mode of action in the rumen. Journal of Animal Science, v.58, p.1518-1527, 1984.

SIMPSON, M.E. Effects of certain antibiotics in vitro cellulose digestibility and volatile fatty acid (VFA) production by ruminal microorganisms. Journal of Animal Science, v.47, p.429, 1978. Supplement 1.

THORNTON, J.H.; OWENS, F.N. Monensin supplementation and in vivo methane production by steers. Journal of Animal Science, v.52, p.628-634, 1981.

VAN KESSEL, J.S.; RUSSELL, J.B. Energetics of arginine and lysine transport by whole cells and membrane vesicles of strain SR, a monensin-sensitive ruminal bacterium. Applied and Environmental Microbiology, v.58, p.969-975, 1992.

YANG, C.M.J.; RUSSELL, J.B. The effect of monensin supplementation on ruminal ammonia accumulation in vivo and the numbers of amino acid-fermenting bacteria. Journal of Animal Science, v.71, p.3470-3476, 1993.

ZINN, R.A; PLASCENCIA, A.; BARAJAS, R. Interaction of forage level and monensin in diets for feedlot cattle on growth performance and digestive function. Journal of Animal Science, v.72, p.2209-2215, 1994.

Recebido em 07.06 .00 